\title{
DESAIN DAN IMPLEMENTASI RESTfUl WEB SERVICES UNTUK INTEGRASI DATA DAN APLIKASI
}

\author{
Herfandi $^{1 *}$, M. Julkarnain ${ }^{2}$, Muhammad Hanif ${ }^{3}$ \\ 1,2,3 Teknik Informatika, Universitas Teknologi Sumbawa \\ email: herfandi@uts.ac.id*
}

\begin{abstract}
Abstrak: Industri (usaha) di bidang kuliner di Indonesia merupakan usaha yang mengalami pertumbuhan yang sangat pesat. Peningkatan kualitas pelayanan pada suatu usaha akan berimplikasi dengan maksimalnya profit yang di dapatkan. Teknologi yang tepat untuk menghubungkan berbagai macam platform adalah web services. Manajemen Geprek Chicken Dinner menggunakan dua aplikasi yang berbeda untuk dalam proses bisnisnya Hal ini tentu menghambat proses bisnis dan memerlukan waktu dan tenaga yang menyebabkan proses bisnis tidak optimal. Karenanya tujuan dari penelitian desain dan implemtasi RESTful web services di Geprek Chicken Dinner. Penelitian ini menghasilkan aplikasin RESTful web services dengan fitur access token dan API key sebagai sistem keamanan dengan metode pengembangan extreme programming. metode black box melibatkan auditor dan ahli IT mendapatkan kesimpulan berhasil dari berbagai jenis pengujian. Aplikasi ini diharapkan mampu sebagai pangkalan untuk semua data yang diproses dan sebagai penghubung antar aplikasi yang akan digunakan oleh manajemen, sehingga aplikasi-aplikasi yang digunakan saling terintegrasi.
\end{abstract}

Kata Kunci : Black box Testing, Extreme programming, Integrasi Data, Kuliner Indonesia, RESTful web services

\begin{abstract}
Industry (business) in the culinary field in Indonesia is a business that is experiencing very rapid growth. Improving the quality of service in a business will have implications for the maximum profit obtained. The right technology to connect various platforms is web services. Geprek Chicken Dinner management uses two different applications for its business processes. This of course hampers business processes and requires time and energy which causes business processes to be not optimal. Therefore, the purpose of research on the design and implementation of RESTful web services at Geprek Chicken Dinner. This research produces RESTful web services applications with access token and API key features as a security system with extreme programming development methods. the black box method involves auditors and IT experts getting successful conclusions from various types of tests. This application is expected to be able to serve as a base for all processed data and as a liaison between applications that will be used by management, so that the applications used are integrated with each other.
\end{abstract}

Keywords : Black Box Testing, Extreme programming, Data Integration, Indonesian Culinary, RESTful web services

\section{PENDAHULUAN}

Industri (usaha) di bidang kuliner di Indonesia merupakan usaha yang mengalami pertumbuhan yang sangat pesat [1]. Masyarakat Indonesia masih memiliki kebiasaan makan di luar rumah [2] hal ini di sebabkan semakin banyaknya usaha bidang kuliner yang menawarkan harga yang murah degan variasi kuliner baru baik dari rasa lokal ataupun mancanegara. Usaha bidang kuliner berperang juga sebagai sumber Pendapatan Asli Daerah (PAD) terutama dari pajak [3]. Situasi tersebut membuat para pimpinan usaha dibidang kuliner harus mampu mengikuti perkembangan zaman agar mampu memberikan pelayanan yang efektif dan efisien bagi para konsumen [4]. Peningkatan kualitas pelayanan pada suatu usaha akan berimplikasi dengan maksimalnya profit yang di dapatkan.

Seiring perkembangan teknologi yang bisa di manfaatkan pada bidang usaha. Maka akan ada nilai tambah dari segi efisiensi waktu, tempat dan tenaga. Pemanfaatan teknologi di bidang bisnis sering kali menggunakan berbagai macam platform aplikasi sebagai pendukung kebutuhan bisnis. Hal ini tentunya membutuhkan penghubung antara aplikasi agar saling terintegrasi. Teknologi yang tepat untuk menghubungkan berbagai macam platform adalah web services [5]. Web services memungkinkan aplikasi yang dikembangkan berinteraksi dengan berbagai jenis perangkat lunak dengan platform dan sistem operasi yang sama ataupun berbeda [1]. Penggunaan web services memudahkan pihak pebisnis dalam melakukan scale up bisnisnya [6] seperti yang dilakukan oleh Gojek, yang sekarang sudah menjadi startup decacorn.

Berdasarkan hasil observasi pada Geprek Chicken Dinner (GCD) yang merupakan Usaha Mikro Kecil Menengah (UMKM) yang bergerak dalam bidang kuliner. Usaha inilah yang dijadikan sebagai studi kasus dalam penilitan ini. Dalam menjalankan bisnisnya, tentu tidak lepas dari proses pencatatan data. Mulai dari data penjualan, data stok barang, absensi karyawan sampai dengan data keuangan. Manajemen Geprek Chicken Dinner menggunakan dua aplikasi yang berbeda untuk mencatat data-data tersebut. Aplikasi A yaitu aplikasi Zobaze Pos dan aplikasi B yaitu aplikasi Catatan Keuangan Harian. Aplikasi A untuk data kasir dan aplikasi B untuk pelaporan keuangan. Aplikasi A dipasang di setiap outlet memiliki database masing masing. Begitu pula dengan aplikasi B yang memiliki database-nya sendiri. Masing-masing aplikasi tidak bisa mengakses data dari database aplikasi lain. Hal ini menyebabkan tidak ada integrasi data antara kedua aplikasi tersebut, baik integrasi aplikasi A antar outlet maupun integrasi aplikasi A dengan aplikasi B. Untuk membuat laporan keuangan di aplikasi B, manajemen 
Geprek Chicken Dinner harus mengambil data penjualan semaua outlet terlebih dahulu dari aplikasi A. Dan Untuk mendapatkan data penjualan semua outlet, manajemen Geprek Chicken Dinner perlu untuk login berkali kali di masing masing aplikasi A di setiap outlet. Jika ada data yang tidak sinkron diantara beberapa outlet, maka manajemen perlu untuk mengubah datanya secara manual di masing masing aplikasi. Hal ini tentu menghambat proses bisnis dan memerlukan waktu dan tenaga yang menyebabkan proses bisnis tidak optimal. Seiring berjalannya waktu, seiring semakin banyaknya data bisnis yang diproses, pihak manajemen Geprek Chicken Dinner memutuskan beralih untuk meninggalkan kedua aplikasi tersebut dan memilih aplikasi WhatsApp untuk proses bisnisnya. Tentunya ini merupakan kemunduran dari penggunaan perkembangan teknologi.

Berdasarikan permasalahan yang telah di paparkan maka penelitian ini akan men-desain dan implemtasi RESTful web services di Geprek Chicken Dinner yang diharapkan mempu sebagai pangkalan untuk semua data yang diproses dan sebagai penghubung antar aplikasi yang akan digunakan oleh manajemen, sehingga aplikasi-aplikasi yang digunakan saling terintegrasi.

\section{TINJAUAN PUSTAKA}

Sebagai perbandingan dan sumber acuan pada penelitian ini, maka diperlukan acuan dari penelitian yang telah dilakukan sebelumnya. Berikut ini merupakan rangkuman dari penelitian-penelitian yang dijadikan sebagai rujukan: Penelitian oleh R. Gunawan and A. Rahmatulloh (2018) melakukan implementasi web services untuk mengintegrasikan dua sistem yang berbeda sehingga update data antar sistem dapat dilakukan secara real time. Web services yang di implementasikan pada artikel ini belum memiliki system keamanan pada saat pertukaran data [7]. Sedangkan web services pada artiket menerapkan enkripsi data dengan otentikasi berbasis token sebagai sistem keamanan. Al Isfahani FNugraha FMubarok R et al (2019) melakukan implementasi web services untuk aplikasi pemantau coronavirus disease dapat digunakan oleh masyarakat secara interaktif dan realtime serta integrasi dan pertukaran data yang terjadi pada sisi back end telah berhasil menggabungkan dari empat sumber layanan yang berbeda [8]. Penelitian ini tidak membangun RESTful API server sendangkan pada penelitian ini membangun RESTful API server untuk kebutuhan integrasi data sehingga memudahkan pihak pemilik usaha jika ingin mengembangan aplikasi dengan platform berbeda. R. Rizal and A. Rahmatulloh (2019) dan M. P. Putri and H. Effendi, (2018) penelitian pada kedua artikel ini mengintegrasikan sistem informasi akademik dan perpustakaan dengan menggunakan RESTful web services. Dengan penerapan teknologi web services maka kedua sistem tersebut dapat berkomunikasi dan bertukar data satu sama lainnya
[9], [10]. Perbedaan dengan artikel ini pada objek penelitian dan metode pengembangan yang di gunakan, dimana di artikel ini menjadikan usaha bidang kuliner sebagai objek penelitian dan metode extreme programming sebagai metode pengembangan.

Dengan mempertimbangkan beberapa referensi di atas, maka kekuatan dari penelitian ini yaitu implementasi RESTful web services dengan fitur API key dan access token untuk keamanan web services agar data tidak bisa diakses oleh sembarang orang. Metode pengembangan perangkat lunak extreme programming yang dipilih dikarenakan kelebihan dari metode ini adalah waktu yang dibutuhkan singkat dan mudah menyesuaikan dengan kebutuhan pelanggan. Untuk mempercepat penulisan kode, penelitian ini menggunakan kerangka kerja (framework). Framework yang penulis gunakan adalah framework laravel. Untuk format data, penulis menggunakan format Javascript Object Notation (JSON) karena format JSON lebih banyak digunakan dalam penggunaan $A P I$.

\section{METODE}

\section{A. Tahapan Penelitian}

Tahapan penelitian yang dilakukan pada artiket ini melibatkan metode pengembangan extreme programming, Adapun tujuan dari penggunaan metode tersebut adalah sebagai prosedur tahapan dalam desain dan implementasi [11] RESTful web services agar proses bisa terstruktur dan berjalan secara sistematik. Adapun metode yang digunakan dalam penelitian ini adalah metode penelitian kualitatif, dimana penelitian menekankan aspek pemahaman yang mendalam terhadap suatu permasalahan [12]. Objek tempat penelitian yang di jadikan studi kasus yaitu di Usaha Mikro Kecil Menengah (UMKM) Geprek Chicken Dinner (GCD) Sumbawa. Permasalah yang di alami pada usaha Geprek Chicken Dinner inilah yang menjadi acuan pada artikel untuk mengangkat penelitian desain dan implementasi RESTful web services yang di bangun menggunakan framework laravel dengan basis Bahasa pemrograman PHP [13].

\section{B. Skema Tahapan Penelitian}

Skema Tahapan Penelitian mengadopsi model extreme programming dimana model ini dimodifikasi sesuai dengan tahapan penelitian yang di sertai dengan metode penelitian kualitatif:

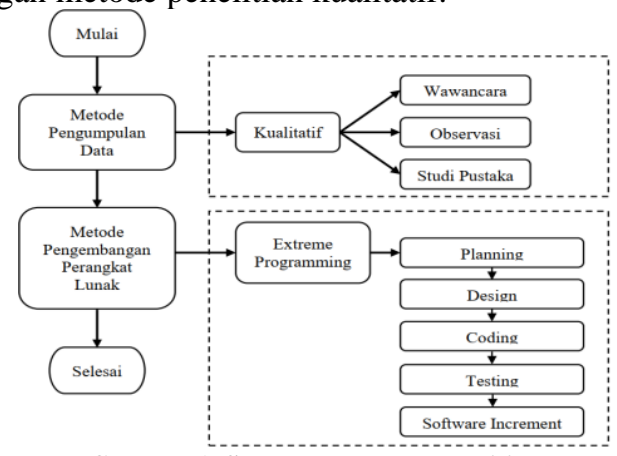

Gambar 1. Skema Tahapan Penelitian 
Tahapan yang ada pada skema alur penelitian yang tegambar, dapat dijelaskan sebagai berikut:

1. Tahapan yang pertama adalah Metode pengumpulan data pada Artikel ini menggunakan kualitatif karena metode ini mengacu pada data dan pemanfaatan teori terdahulu serta hasil analisis menggunakan pendekatan deskriptif. (1) Observasi: proses dilakukan dengan cara melakukan survei lokasi basecamp beserta outlet Geprek Chicken Dinner untuk mendapatkan dan mengumpulkan data yang diperlukan untuk ditampung di RESTful web services. (2) Wawancara: langsung pada melakukan wawancara dengan Mas Fajar selaku Owner Geprek Chicken Dinner pada tanggal 2 November 2020 di basecamp Geprek Chicken Dinner. Wawancara akan berlanjut dikemudian hari melalui daring ataupun tatap muka, sampai mendapatkan semua kebutuhan yang diperlukan dalam membangun RESTful web services. (3) Studi Pustaka: menggunakan mesin pencari https://scholar.google.com untuk mencari jurnal online yang ter-akreditasi sinta sebagai referensi dan data-data dari pihak Geprek Chicken Dinner untuk mendukung pembuatan aplikasi.

2. Metode pengembangan perangkat lunak muggunakan extreme programming dikarenakan kubutuhan dari user Geprek Chicken Dinner yang ingin aplikasinya agar cepat di selesaikan sehingga aplikasi yang akan bangun sejalan dengan proses pengembangan yang ada di dalam extreme programming. (1) Planning: proses pada tahapan dilakukan setelah mendapatkan data yang dibutuhkan dan didapatkan melalui wawancara, observasi dan studi pustaka. Perencanaan dilakukan dengan cara meeting dengan manajemen Geprek Chicken Dinner. (2) Design: Pada tahapan ini akan dibuat perancangan Web service Geprek Chicken Dinner sesuai dengan hasil analisa kebutuhan pada tahap sebelumnya. Adapun proses perancangannya menggunakan teknik pemodelan yaitu Unified Modelling Language (UML) dikarenakan pada pembangunan aplikasi menggunakan paradigma Object Oriented Programming (OOP) [14]. Dalam membangun aplikasi pelayanan penduduk pada penelitian ini, Use Case Diagram-nya bisa dilihat pada Gambar 2.

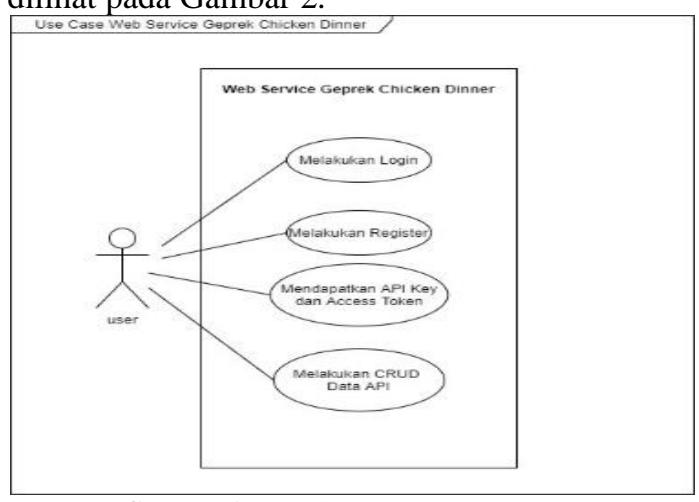

Gambar 2. Use Case Diagram User
Pada Use Case Diagram di atas dapat dilihat bahwa user web services ini yaitu developer Geprek Chicken Dinner dapat melakukan login, melakukan register, mendapatkan API key dan access token, dan melakukan CRUD (Create, Read, Update, Delete) data API.

Class Diagram digunakan untuk menggambarkan penjelasan tiap kelas didalam model desain bahwa pada aplikasi yang dibuat terdapat hubungan antar kelas dan dapat dilihat pada Gambar 3.

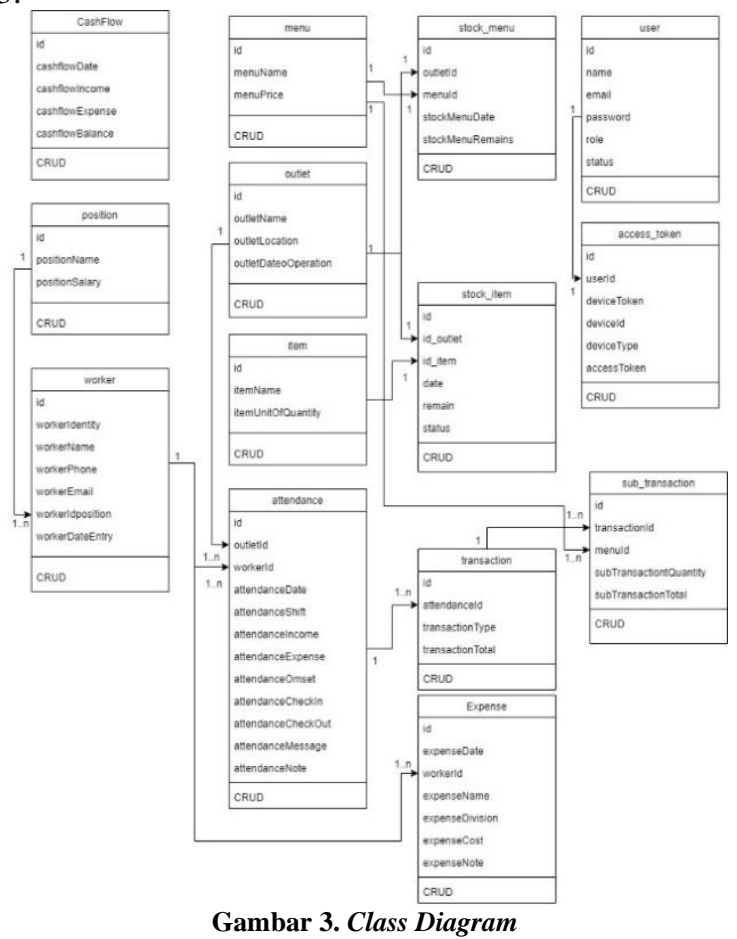

Gambar 3 menggambarkan setiap Class dan dapat terlihat berhubungan antara Class satu dengan dengan Class lain serta terdapat beberapa Class yang memiliki fungsi create, record, update, dan delete. Sistem database yang digunakan pada aplikasi adalah MySQL karna merupakan sistem database populer serta platform database free software. (3) Coding: tahap ini menggunakan text editor Visual Studio Code untuk implementasi aplikasi. (4) Testing: tahap ini dilakukan pengujian sistem yang telah implementasi. Metode pengujian black box testing digunakan untuk melakukan serangkaian pengujian berdasarkan masukan (input) sesuai dengan kebutuhan fungsi sebuah program yang telah dibuat [15]. (5) Software Increment: Tahap ini merupakan tahap dari model Extreme programming yang dilakukan setelah web services di testing. Sistem yang sudah jadi diupload ke server dan dijalankan serta dilakukan pemeliharaan. Pemeliharaan termasuk juga dalam memperbaiki kesalahan yang tidak ditemukan pada langkah sebelumnya. 


\section{HASIL DAN PEMBAHASAN}

Proses desain dan implementasi RESTful web services dilakukan dengan menggunakan bahasa pemrograman PHP dengan framework laravel. Hasil rancang bangun sistem aplikasi RESTful web services meliputi sejumlah sub-bagian sub-window sebagai berikut:

\section{A. Sub Window dari Form Login Admin:}

Form ini akan memberikan hak akses kepada admin untuk menggunakan aplikasi. Form Login admin terdiri dari textbox e-mail address, textbox password dan tombol login. Tombol login berfungsi untuk memproses email dan password sudah sesuai atau tidak, label register untuk mendaftarkan diri dan forgot your password untuk lupa password user bisa di lihat pada Gambar 4.

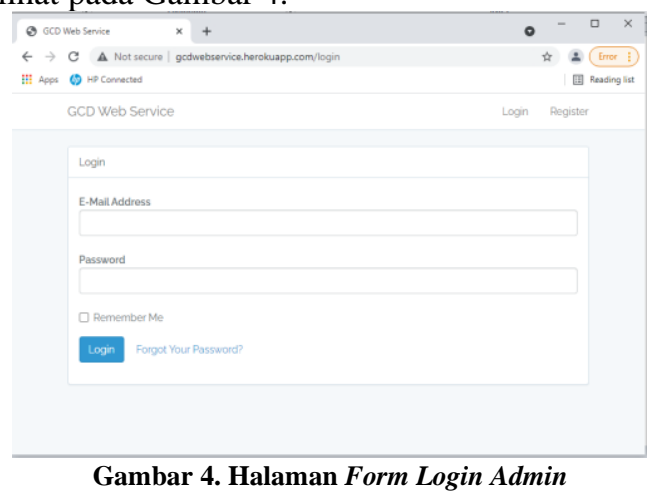

\section{B. Sub Window dari Form Dashboard Admin dan Dokumentasi}

Menu Dashboard setelah dari Form Login Admin. Menu Dashboard Admin bisa di lihat di Gambar 5 yang langsung menampilkan API key dan access token yang siap digunakan untuk tim pengembang aplikasi lain yang akan menggunakan RESTful web services agar bisa terintegrasi dalam satu sitem database yang sama.

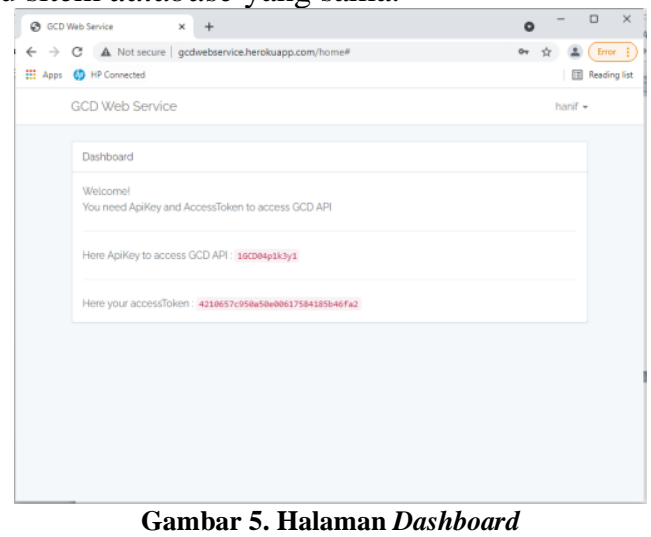

\section{Deploy}

Web services sudah di deploy sehingga bisa diakses secara online. Url web services ini adalah http://gcdwebservice.herokuapp.com. Dengan tampilan database yang sudah di deploy agar bisa diakses secara online yang bisa dilihat pada Gambar 6.

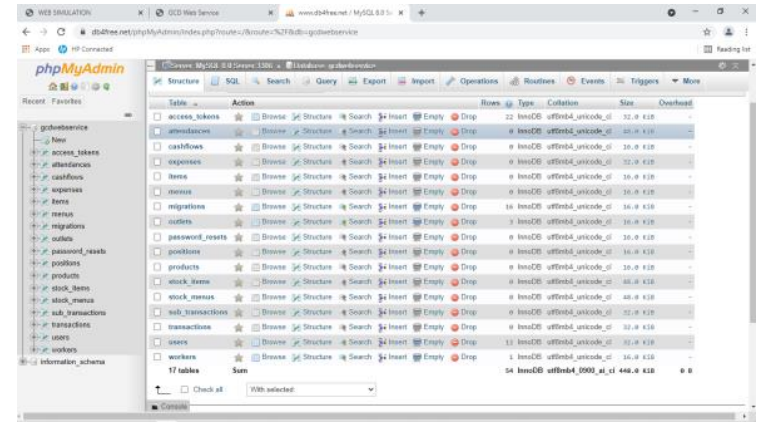

Gambar 6. Tampilan database

\section{Simulasi}

Tahapan simulasi dalam penggunaan Web services yaitu Setelah mendapatkan API key dan access token. User dapat mengakses data API dengan mencantumkan API key dan access token di header request. Dalam simulasi ini, penulis menggunakan sebuah web simulasi yang berfungsi sebagai client. Gambar 7 menjelaskan penulis menggunakan sebuah web simulasi yang dibuat untuk mengakses data API di Geprek Chicken Dinner web services baik dengan Method GET, POST, PUT dan DELETE.

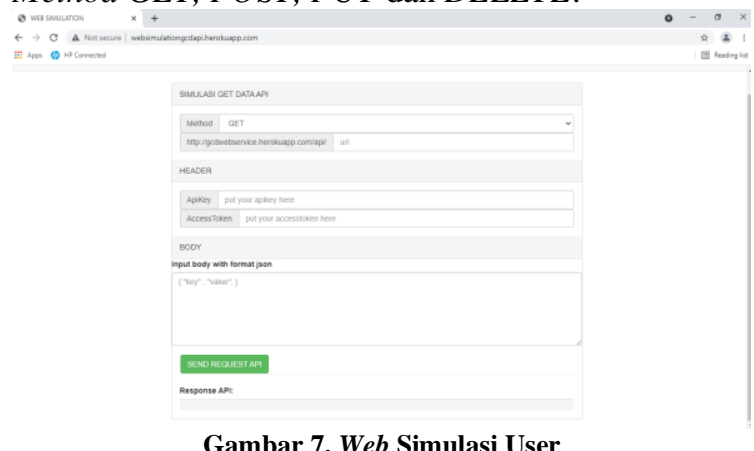

Berikut salah satu penggunaan method yang ingin di simulasikan. Gambar 8 menunjukkan penulis mencoba mengakses data API menggunakan method DELETE untuk menghapus sebuah data outlet yang sudah ada. Data dengan id nomor lima yang akan dihapus datanya.

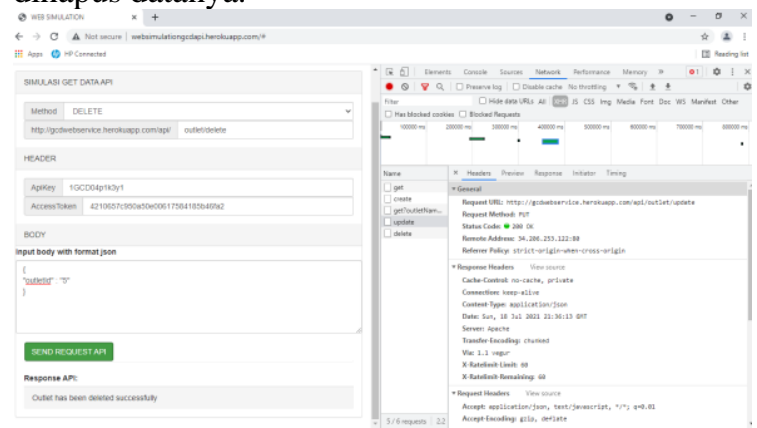

Gambar 8. Simulasi menggunakan Method DELETE

Gambar 9 menunjukkan tampilan database web services sebelum dilakukan simulasi menggunakan method DELETE. Data dengan id nomor lima yang akan dihapus. 


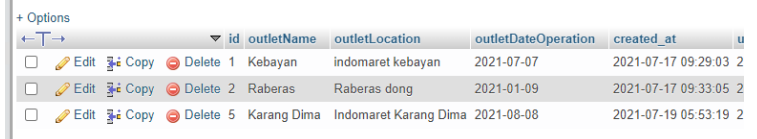

Gambar 9. Tampilan database web services sebelum delete

Gambar 10 menunjukkan tampilan database web services sesudah dilakukan simulasi menggunakan method DELETE. Data dengan id nomor lima sudah berhasil dihapus sesuai dengan request $A P I$ dari web simulasi.

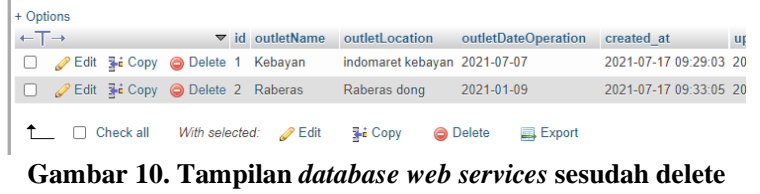

\section{E. Pengujian Sistem}

Pengujian Sistem yaitu menggunakan metode pengujian black box yaitu pengujian pada sistem user dimana dalam pengujian smelibatkan auditor Bapak Fajar dan Bapak Herfandi sebagai ahli IT. Untuk Hasil pengujian black box sebagaimana disajikan pada Tabel 1.

Tabel 1. Pengujian Sistem dengan black box

\begin{tabular}{|c|c|c|}
\hline $\begin{array}{c}\text { Aktivitas dan } \\
\text { Fungsional } \\
\end{array}$ & Hasil & Kesimpulan \\
\hline $\begin{array}{c}\text { Memasukkan data } \\
\text { login yang valid } \\
(\text { Login })\end{array}$ & $\begin{array}{l}\text { Menampilkan } \\
\text { halaman } \\
\text { Dashboard }\end{array}$ & Berhasil \\
\hline $\begin{array}{l}\text { Memasukkan data } \\
\text { login yang tidak } \\
\text { valid (Login) }\end{array}$ & $\begin{array}{l}\text { Menampilkan } \\
\text { pesan error }\end{array}$ & Berhasil \\
\hline $\begin{array}{c}\text { Mengisi seluruh } \\
\text { form sesuai format } \\
\text { dan klik registrasi } \\
\text { (Register) }\end{array}$ & $\begin{array}{l}\text { Menampilkan } \\
\text { halaman } \\
\text { dashboard } \\
\text { dengan } \text { user } \\
\text { baru } \\
\text { terotentikasi }\end{array}$ & Berhasil \\
\hline $\begin{array}{l}\text { Mengisi hanya } \\
\text { sebagian form dan } \\
\text { klik registrasi } \\
\text { (Register) }\end{array}$ & $\begin{array}{l}\text { Menampilkan } \\
\text { pesan "please } \\
\text { fill out this } \\
\text { field" pada } \\
\text { form yang } \\
\text { belum di isi }\end{array}$ & Berhasil \\
\hline $\begin{array}{c}\text { Mengklik } \\
\text { generate access } \\
\text { token (Dashboard) }\end{array}$ & $\begin{array}{l}\text { Menampilkan } \\
\text { access token } \\
\text { user }\end{array}$ & Berhasil \\
\hline $\begin{array}{l}\text { Mengirim Request } \\
\text { dengan } \\
\text { mencantumkan } \\
\text { API key dan } \\
\text { access token yang } \\
\text { sesuai (Akses Data } \\
\text { API) }\end{array}$ & $\begin{array}{c}\text { Menampilkan } \\
\text { response API } \\
\text { sesuai dengen } \\
\text { request API }\end{array}$ & Berhasil \\
\hline $\begin{array}{l}\text { Mengirim Request } \\
\text { dengan } \\
\text { mencantumkan } \\
\text { API key dan } \\
\text { access token yang }\end{array}$ & $\begin{array}{l}\text { Menampilkan } \\
\text { failed response } \\
\text { API dengan } \\
\text { pesan } \\
\text { "unauthorized" }\end{array}$ & Berhasil \\
\hline
\end{tabular}

tidak sesuai

(Akses Data API)

\begin{tabular}{ccc} 
Mengirim Request & & \\
method POST/ & Menampilkan & \\
PUT/ DELETE & $\begin{array}{c}\text { response API } \\
\text { dengan body form }\end{array}$ & Berhasil \\
yang sesuai & $\begin{array}{c}\text { sesuai dengen } \\
\text { request API }\end{array}$ & \\
dengan format & & \\
(Akses Data API) & & \\
\hline Mengirim Request & & \\
method POST/ & & \\
PUT/ DELETE & Menampilkan & \\
dengan body form & failed response & Berhasil \\
yang tidak sesuai & API & \\
dengan format & & \\
(Akses Data $A P I)$ & & \\
& &
\end{tabular}

\section{KESIMPULAN DAN SARAN}

Berdasarkan penelitian yang telah lakukan maka di tarik kesumpulan: (1) Metode pengembangan perangkat lunak yang digunakan ialah Extreme programming. (2) Sistem integrasi data dan aplikasi pada Geprek Chicken (GCD) Sumbawa berhasil dibangun dengan menerapkan RESTful web services Technology dengan desain menggunakan pendekatan Unified Modelling Language (UML). (3) Bahasa pemrograman yang digunakan yaitu PHP (PHP: Hypertext Preprocessor), dengan framework laravel dan database menggunakan MySQL. (4) Pengujian perangkat lunak dengan metode black box melibatkan auditor dan ahli IT mendapatkan kesimpulan berhasil dari berbagai jenis pengujian. (5) RESTful web services yang dibangun memiliki fitur access token dan API key untuk enkripsi data dan otentikasi agar web services tidak bisa diakses oleh sembarang orang serta berhasil disimulasikan dengan menggunakan web simulasi sebagai client.

Pembuatan RESTful web services di Geprek Chicken Dinner ini masih terdapat banyak kekurangan seperti tidak adanya administrator dan kurang optimalnya penggunaan access token. Adapun saran terhadap RESTful web services ini untuk pengembangan selanjutnya danap mengoptimalkan fungsi access token dengan menerapkan metode otorisasi terhadap masing masing user sesuai dengan rules-nya serta menambahkan fitur administrator.

\section{DAFTAR PUSTAKA}

[1] S. N. Haq, A. Fitri, ) Sekolah, T. Ekonomi, and I. Sebi, "IMPLEMENTASI PROPHETIC LEADERSHIP PADA AYAM GEPREK JUARA RAWAMANGUN JAKARTA TIMUR)," 2021. [Online]. Available: https://jurnal.umj.ac.id/index.php/taraadin

[2] F. Ulfa, O. Woro Kasmini Handayani Epidemiologi dan Biostatistik, and J. Ilmu Kesehatan Masyarakat, "227 HIGEIA 2 (2) (2018) HIGEIA JOURNAL OF PUBLIC HEALTH RESEARCH AND 
DEVELOPMENT KEJADIAN DEMAM TIFOID DI WILAYAH KERJA PUSKESMAS PAGIYANTEN Info Artikel," 2018. [Online]. Available: http://journal.unnes.ac.id/sju/index.php/higeia

[3] A. Dahuri, D. Harjo, and C. Balancia, "Analsis Strategi Peningkatan Penerimaan Pajak Restoran Kota Bekasi Tahun 2020 Di Masa Pandemi Covid-19 (Studi Kasus Pada Badan Pendapatan Daerah Kota Bekasi Di Masa Pandemi Covid-19),” 2021. [Online]. Available: http://ojs.stiami.ac.id

[4] A. Pelayanan Penduduk Desa Labuhan Sumbawa, E. Ramdani, S. Dwiasnati, A. Susilo Yuda Irawan, and R. Habibie Sukarna, "Daerah Khusus Ibukota Jakarta 11650." [Online]. Available: https://scholar.google.com

[5] Yogiswara and Dimas Rayi Astriyanto, "PENERAPAN WEB SERVICE DAN FIREBASE NOTIFICATION PADA PENGEMBANGAN APLIKASI GERAKAN NASI BUNGKUS JEMBER BERBASIS ANDROID," JIP (Jurnal Informatika Polinema), vol. 4, no. 2, p. 161, Aug. 2018, doi: https://doi.org/10.33795/jip.v4i2.

[6] N. Rachman and P. Irfan, "Aplikasi Kurir Mobil Pick Up Berbasis mutli Platform (Multi Platform Pick Up Car Courier Application)," vol. 2, no. 3, pp. 166-173, 2020.

[7] R. Gunawan and A. Rahmatulloh, "Jurnal Ilmiah Setrum Implementasi Web Service pada Sistem HostTo-Host Pembayaran Biaya Akademik," Jurnal Ilmiah Setrum, vol. 7, no. 2, pp. 320-328, 2018.

[8] F. al Isfahani, F. Nugraha, R. Mubarok, A. Rahmatulloh, and S. Artikel, "INFORMASI ARTIKEL A B S T R A CT," vol. 2, no. 1, pp. 33-39, 2019.

[9] R. Rizal and A. Rahmatulloh, "RESTful Web Service untuk Integrasi Sistem Akademik dan Perpustakaan Universitas Perjuangan.”

[10] F. Bimantoro, I. Bagus Ketut Widiartha, I. Gede Pasek Suta Wijaya, and A. Yudo Husodo, "INTEGRASI SISTEM INFORMASI KEPUASAN BELAJAR MENGAJAR PROGRAM STUDI TEKNIK INFORMATIKA DENGAN SISTEM INFORMASI AKADEMIK UNRAM MENGGUNAKAN WEB SERVICE (Integrating Teaching and Learning Satisfaction with Academic Information System Using Web Service)." [Online]. Available: http://jtika.if.unram.ac.id/index.php/JTIKA/

[11] R. I. Borman, A. T. Priandika, and A. R. Edison, "Implementasi Metode Pengembangan Sistem Extreme Programming (XP) pada Aplikasi Investasi Peternakan," Jurnal Sistem dan Teknologi Informasi (Justin), vol. 8, no. 3, p. 272, Jul. 2020, doi: 10.26418/justin.v8i3.40273.

[12] Haryono and Cosmas Gatot, Ragam Metode Penelitian Kualitatif Komunikasi. CV Jejak (Jejak Publisher), 2020.
[13] D. P. D. Dissanayake, "REST API Service Middleware A dissertation submitted for the Degree of Master of Information Technology," 2018.

[14] D. S. Maylawati, W. Darmalaksana, and M. A. Ramdhani, "Systematic Design of Expert System Using Unified Modelling Language," in IOP Conference Series: Materials Science and Engineering, Jan. 2018, vol. 288, no. 1. doi: 10.1088/1757-899X/288/1/012047.

[15] Roman and Adam, Black-Box Testing Techniques. Springer, 2018. 